phate $\left(\mathrm{P}_{2} \mathrm{O}_{5}\right)$ or $10 \mathrm{mgm}$. nitrate nitrogen per cubic metre) usually extended down to $150-200$ metres, and in this connexion red algæ have been found growing in this sea down to 130 metres, far below the limit to which sufficient light could penetrate in the more turbid northern waters. $\dagger$ Thus it would seem that the very scarcity of nourishment and resulting sparseness of sub-surface life enables light to penetrate far into the water for plants there to utilise the minute quantities of phosphate and nitrate which diffuse up from the meagre bottom store. Perhaps, indeed, in the Mediterranean the region most favourable for planktonic organisms may be far removed from the surface, at, say, 100 metres, where a sufficiency both of light and of nutrient salts are found together. This is far lower than is found anywhere in waters around Great Britain. Experimental data on the amount and quality of the light penetrating to such depths and of its suitability for photosynthesis should prove illuminating.

† Harvey, H. W., " Biological Chemistry and Plyysics of Sea Water". Cambritge, 1928.
The concentrations of both phosphate and nitrate decrease going eastward from the Straits of Gibraltar. In the Egean Sea phosphates were not detected at any depth, and nitrates were very poor. It is manifest that life cannot flourish on any considerable scale in such impoverished waters. In the Straits of Messina nitrate appeared to be comparatively high, apparently due to vertical mixing, but it was unaccompanied by phosphate and was presumably therefore of little value.

The scarcity of nutrient salts in the Mediterranean is attributed by Thomsen to the exchange of water through the Straits of Gibraltar, since Atlantic surface water, already poor in nitrate and phosphate, runs in over the outgoing bottom current of Mediterranean water. This exchange of water has been well established by several vessels, including the Dana, and Thomsen's own analyses in the Straits and the Alboran Sea testify to the impoverishment of the inflowing Atlantic surface water, at any rate in April and June.

L. H. N. C.

\title{
Acoustic and Telephone Measurements
}

$\mathrm{N}$ a paper read by $\mathrm{H}$. R. Harbottle to the Institution of Electrical Engineers on April 8, a brief description is given of some of the work carried out in the research section of the British Post Office. He begins by discussing electro-acoustic and acousto-electric measurements of instruments. $\mathrm{He}$ next describes voice-ear measurements on microphones and receivers, and finally deals with mechanical tests by means of which rapid acceptance tests can be made and estimates given of the commercial life of instruments.

Mr. Harbottle attributes the progress made during recent years to the methods invented of expressing the results of measurements in telephony by reference to absolute units. These methods followed on the invention and development of the thermionic valve. This has enabled acoustic pressures and velocities to be measured accurately, and has led to the rapid advances made in radio-telephony. This in turn has promoted world-wide telephonic communication.

To enable this to be done, an international com mittee had to be formed, called the C.C.I.-Comité Consultatif International des Communications Téléphoniques à grande distance-the objects of which were the formulation of correct methods of measurement. Standard instruments were required which had to give a constant response over the range at which they were used. At the present time this can only be achieved by the use of insensitive instruments in which the mechanical resonances have been removed outside the working range by increasing or diminishing the stiffness. The output is then raised by a thermionic valve amplifier suitably applied. A wide field has been found for these instruments in broadcasting, sound pictures, and gramophone reproduction.

The instrument used at the present time as a work- ing standard in most acousto-electric and electroacoustic measurements is a condenser microphone. It consists of a thin aluminium diaphragm, goldplated to prevent oxidisation, forming one plate of the condenser, the other being a circular insulated brass electrode. This is grooved, and is fixed at a small distance away from the other plate. The space between them is practically sealed, and so adds 'stiffness' to the diaphragm. Due to this, the frequency of natural resonance is effectively suppressed.

The microphone is polarised by applying 200 volts across it. Its vibrations cause variations in the capacitance, and consequently it acts like a generator producing electric currents. It is calibrated by one of three methods-the thermophone method, recommended by the C.C.I., the Rayleigh dise method, or the compensator method. The results obtained by these methods have been found by the Post Office to agree satisfactorily.

By means of an automatic device the life test of a carbon microphone can be reduced to about onefiftieth of the normal time taken. A current is first switched on--this represents the lifting of the receiver from the switch hook. A klaxon is next operated momentarily-this simulates the removal of the receiver by the subscriber; 7.5 seconds later the microphone is subjected to a rhythmic 'howl-warble" tone for 7.5 seconds, and this tone is repeated seven times at intervals of 7.5 seconds. At the end of $1 \frac{1}{2}$ minutes the klaxon is momentarily operated and the current switched off. There is then an interval of 1.5 minutes and the cycle begins again. In a week's time the wear on the telephone is the same as that made by a subscriber who in a year makes a thousand calls.

\section{South Sandwich Islands *}

r [HE first of the two Discovery Reports before us is the list of stations 137 to 433 made by R.R.S. William Scoresby in the seas between South Georgia, the Falkland Islands, and the South Shetlands from January 1928 to May 1929, and other stations made

* Discovery Reports. Issued by the Discovery Committee, Colonial Office, London, on behalf of the Government of the Dependencies of the Falkland Islands. Vol. 3. Station List, 1927-1929. Pp. $132+10$ plates. 14s. 6d. net, The South Sandwich Islands. By Dr. Stanley Kemp and A. L. Nelson; with a Report on Rock Specimens, by Dr. G. W. Tyrrell. Pp. 133-198+plates 11-31. 18s. net. (Cambridge At the University Press, 1931.)

No. 3263, VoL. 129] by members of the Discovery investigations staff from whale factory ships about the South Sandwich Islands and in the Ross Sea. This follows the first station list published in an earlier volume of the Discovery Reports.

The second report under notice deals with the South Sandwich Islands. These islands were discovered by Cook in 1775 and Bellingshausen in 1819, but they lie in stormy and frequently ice-invested seas off the track of most antarctic expeditions, and have been rarely visited except by sealers and whalers until the Discovery spent twenty days among the group in 